\title{
COMENTARIOS SOBRE EL PRINCIPIO DE IGUALDAD Y GÉNERO EN LA CONSTITUCIÓN DE CÁDIZ (1812)
}

ROSA MARÍA RICOY CASAS 
SUMARIO

1. EL CONCEPTO CIUDADANO, SUJETO DE DERECHOS, EN LA CONSTITUCIÓN DE CÁDIZ. 2. LA SUCESIÓN EN LA CORONA Y LOS TÍTULOS DE CONSORTE, REGENTE, TUTOR, PRÍNCIPE E INFANTA. 3. LOS TÍTULOS NOBILIARIOS Y LA ABOLICIÓN DE LOS SEÑORÍOS. 4. CONCLUSIONES. 5. BIBLIOGRAFÍA. 


\title{
COMENTARIOS SOBRE EL PRINCIPIO DE IGUALDAD Y GÉNERO EN LA CONSTITUCIÓN DE CÁDIZ (1812)
}

POR

\author{
ROSA MARÍA RICOY CASAS
}

Universidad de Vigo

\section{EL CONCEPTO CIUDADANO, SUJETO DE DERECHOS, EN LA CONSTITUCIÓN DE CÁDIZ}

El art. 1 de la Constitución de Cádiz establece que «la Nación española es la reunión de todos los españoles de ambos hemisferios», y el art. 5 precisa que son españoles «todos los hombres libres nacidos y avecindados en los dominios de las Españas, y los hijos de estos» (a los citados se añaden los extranjeros que hayan obtenido de las Cortes cartas de naturaleza, los que sin ella lleven diez años de vecindad, y los libertos desde que adquieran la libertad en las Españas). Según algún autor, todavía no hemos llegado al apartado de los derechos políticos, se está hablando de los derechos civiles, que se les reconocen expresamente a los hombres libres, es decir, que se excluye de ese reconocimiento a las mujeres y a los esclavos ${ }^{1}$.

${ }^{1}$ CLAVERO, B., «Cara oculta de la Constitución: sexo y trabajo», Revista de las Cortes Generales, núm. 10, 1987, pp. 11-25. En esta época, en España, la esclavitud era una práctica habitual, y no se abolió en las colonias españolas legalmente hasta finales del siglo XIX. 
En cuanto a los derechos políticos, corresponden a los ciudadanos. Son ciudadanos aquellos españoles que por ambas líneas traen su origen de los dominios españoles de ambos hemisferios y están avecindados en cualquier pueblo de los mismos dominios (art. 18). Se consideraba también ciudadano al extranjero que gozando ya de los derechos del español, obtuviere de las Cortes carta especial de ciudadano (art. 19). Para que el extranjero pudiera obtener de las Cortes esta carta, debería estar casado con una española, y haber traído o fijado en las Españas alguna invención o industria apreciable, o adquirido bienes raíces por los que pague una contribución directa, o estableciéndose en el comercio con un capital propio o considerable a juicio de las Cortes, o hecho servicios en bien y defensa de la Nación (art. 20).

Ya se han visto las restricciones para ser considerado español, pero no todos los españoles son ciudadanos. A los españoles originarios de África (art. 10) que se llamó «las castas», les queda abierta la puerta del merecimiento para el ingreso en la ciudadanía, con condiciones que se explican en el artículo 22. Asimismo, los artículos 24 y 25 exponen los motivos por los que se pierde la calidad de ciudadano español y por los que se suspende el ejercicio de los correspondientes derechos.

En el propio «discurso preliminar leído en las Cortes al presentar la Comisión de Constitución el proyecto de ella» se señala que «la apreciable calidad de ciudadano español no sólo debe conseguirse con el nacimiento o naturalización en el reino, debe conservarse en conocida utilidad y provecho de la Nación; y por eso se señalan los casos en que puede perderse o suspenderse, para que así los españoles sean cuidadosos y diligentes en no desprenderse de lo que para ellos debe ser tan envidiable».

Así, el art. 25 de la Constitución de Cádiz establece la suspensión en el ejercicio de los derechos de los ciudadanos españoles: en virtud de interdicción judicial por incapacidad física o moral, por el estado de deudor quebrado, o de deudor a los caudales públicos, por el estado de sirviente doméstico; por no tener empleo, oficio o modo de vivir conocido; por hallarse procesado criminalmente; y desde el año 1830 deberían saber leer y escribir los que de nuevo entraran en el ejercico de los derechos de ciudadano.

Debe recordarse en relación al estado de sirviente doméstico, aunque ello no fuera extensible para todos los casos, que la esclavitud acabó suprimiéndose por R.O. de 7 de octubre de 1886, de un modo un tanto tardío y bastante posterior a la Constitución de Cádiz² . En relación a esta cuestión, el artículo 5.4 establece

2 Siguiendo a GARCÍA-GALlO, A.: Estudios de Historia del Derecho Privado, Sevilla, Universidad de Sevilla, 1982, p. 53, va a quedar establecida de manera absoluta la condición libre de todos los hombres, y el reconocimiento de su capacidad jurídica. 
que son españoles (...) «los libertos desde que adquieran la libertad en las Españas». Tal vez por ello resulta tan sintomático de dicha situación el propio título de un artículo: «Amos y sirvientes, ¿primer modelo constitucional?» ${ }^{3}$.

En relación a la suspensión a causa de «no tener empleo, oficio o modo de vivir conocido», debe señalarse que en el reinado de Fernando VII, todas las disposiciones dictadas contra vagos y gitanos durante el reinado de Carlos III, se reiterarán en plena época de la Codificación, por la Real Cédula de 22 de agosto de 1814, y de forma más rotunda en la Real Orden de 11 de enero de 1827 (En el Auto que el Consejo de Castilla manda a la Real Chancillería de Granada el 24 de diciembre de 1817, se insta a acabar con los excesos de los llamados gitanos, un tipo de vagabundos).

La repercusión de tales medidas contra los vagabundos se verá reflejada en la legislación posterior a la vigencia de la propia Constitución de Cádiz, pudiendo destacar, en este sentido, la Ley de Vagos de 1845, así como el concepto legal que de vago realiza el Código penal de 1850 (arts. 258 a 266) ${ }^{4}$. Tal vez sobran los comentarios con lo expresado por un autor ya en el siglo XIX al afirmar que «las leyes sobre vagos son hoy, por más que sea doloroso reconocerlo, en manos de los gobiernos una arma política para refrenar la rebeldía de las masas, y en manos de los partidos un pretexto de persecución y venganza» 5 .

El artículo 248 se centra en un aspecto procesal indicando que «en los negocios comunes, civiles y criminales no habrá más que un solo fuero para toda clase de personas». Esta idea junto con la mención que realiza al principio de igualdad al hablar de "leyes justas e igualitarias» ${ }^{6}$, no debe confundirse con la igualdad formal de todos los ciudadanos, pues según se ha señalado, el ejercicio del derecho de ciudadano se suspendía, entre otros, por el estado de sirviente doméstico o por no tener empleo, oficio o modo de vivir conocido, en virtud de su artículo 25.

La constitución establecía el sufragio universal masculino indirecto, la mayor parte de las investigaciones dedicadas a su estudio omiten o minusvaloran la in-

3 CLAVERO, B.: Amos y sirvientes, ¿primer modelo constitucional?, en Anuario de Historia del Derecho Español, 56, 1986.

4 MARTÍNEZ DHIER, A.: La igualdad jurídica de todos los individuos ante la ley: «la vagancia» en la Constitución de Cádiz, en Revista de la Facultad de Ciencias Sociales y Jurídicas de Elche, Vol.1, 2009, pp. 61 y 63.

5 ÁLVAREZ MARTÍNEZ, C.: Comentarios al Código penal, Tomo I, Madrid, 1848, p.217, citado por MARTÍNEZ DHIER, A.: La igualdad jurídica de todos los individuos ante la ley: "la vagancia» en la Constitución de Cádiz, en Revista de la Facultad de Ciencias Sociales y Jurídicas de Elche, Vol. 1, 2009, p. 65.

${ }^{6}$ Constitución de Cádiz habla de «leyes justas e igualitarias» de modo que no sólo han de ser aplicadas con independencia de las personas, sino que, en sí mismas no pueden contener discriminaciones. 
fluencia que la revolución liberal y burguesa española tuvo al transformar los imperio colonial español en provincias de un nuevo Estado, y convertir en nuevos ciudadanos a los antiguos súbditos del absolutismo, y que incluía en su definición de ciudadanos españoles no solo a los europeos, o sus descendientes americanos, sino también a las castas y a los indígenas de los territorios de América, lo que se tradujo, en tercer lugar, en su trascendencia para las nacientes legislaciones americanas. La cuestión americana estaba planteada, por tanto, desde el primer artículo. El Estado liberal tenía parámetros ultraoceánicos.

En el artículo 22 se reconocía a los mulatos la nacionalidad española -Derechos civiles - y en el artículo 29 les privaba de la condición de ciudadanos, es decir, de los derechos políticos. Esta medida fue una estrategia de los peninsulares para reducir el número de diputados americanos, ya que la ley electoral planteaba un sufragio universal proporcional a la población. Así, los representantes peninsulares se aseguraban un número de diputados similar al de los americanos, al excluir a casi seis millones de mulatos americanos de los derechos políticos.

Recordando la idea expresada anteriormente por algún autor a colación de los primeros artículos de la Constitución de Cádiz, todavía no hemos llegado al apartado de los derechos políticos, se está hablando de los derechos civiles, que se les reconocen expresamente a los hombres libres, es decir, que se excluye de ese reconocimiento a las mujeres y a los esclavos: "Se dice hombre porque se excluye a la mujer; se habla en masculino porque se elimina el femenino; se predica un sujeto español porque no se considera siquiera la posibilidad de que la española entre»... «Desde el debate en comisión al acuerdo de pleno, ni como bipótesis ha entrado el sujeto femenino. Media sociedad ya queda excluida de aquel que se nos dice sufragio universal»?

Aunque las primeras reivindicaciones de los derechos de las mujeres se sitúan en el contexto del movimiento ilustrado, e incluso en el marco de la Revolución francesa que clavó en su mástil la consigna liberté, égalité, fraternité, la Ilustración no cumplió sus promesas en lo que a la mujer se refiere, quedando lo femenino como aquel reducto que las Luces no supieron o no quisieron iluminar. En efecto, en aquella

7 CLAVERO, B., «Cara oculta de la Constitución: sexo y trabajo», Revista de las Cortes Generales, núm. 10, 1987, pp. 11-25

${ }^{8}$ MOLINA PETIT, C.: El feminismo en la crisis del proyecto ilustrado, Sistema, no 99, 1990, p. 135. Sobre estas cuestiones resulta muy interesante la lectura de: MOLINA PETIT, C.: Dialéctica feminista de la Ilustración, Anthropos, Madrid, 1994; PULEO, A.: La Ilustración olvidada. La polémica de los sexos en el siglo XVIII. Condorcet, De Gouges, De Lambert y otros, Anthropos, Madrid, 1993; PULEO, A.: Figuras del otro en la Ilustración francesa. Diderot y otros autores, Escuela Libre Editorial, Fundación ONCE, Madrid, 1996. La ilustración no cumplió las expectativas de las mujeres precisamente en un siglo fecundo por definición: ANSUÁTEGUI ROIG, F.J.: Orígenes doctrinales de la libertad de expresión, Universidad Carlos III de Madrid y Boletín Oficial del Estado, Madrid, 1994, p. 289. 
Francia revolucionaria la República estaba dispuesta a agradecer y a condecorar a las mujeres por los servicios prestados, pero no estaba dispuesta a reconocerles otra función que la de madres y esposas (de los ciudadanos)9. Tal vez por esta razón, BLUNTSCHLI, en el siglo XIX, ha señalado que la expresión francesa «l'état c'est l'homme» no sólo expresa que el Estado es el hombre, sino que indica que el Estado representa la naturaleza masculina ${ }^{10}$.

No obstante, una vez que las mujeres habían sentado el precedente de iniciar un movimiento popular armado, no iban a cejar en su afán de no ser retiradas de la vida política. Cuando las mujeres quedaron excluidas de la reunión de los tres estados para redactar y presentar sus quejas al rey comenzaron a redactar sus propios cahiers de doléance, autodenominándose «el tercer Estado del tercer Estado». Pero esta actividad política fue detenida. Los clubes de mujeres fueron cerrados por los jacobinos en 1793, y en 1794 se prohibió explícitamente la presencia de mujeres en cualquier tipo de actividad política y aquellas que tuvieron una participación política significativa, del signo ideológico que fuese, compartieron el mismo final: la guillotina o el exilio. Un ejemplo ha sido Olympe de Gouges, que compartió con la Reina María Antonia la misma suerte: la guillotina. Así pues, las mujeres no podían subir a la tribuna, pero sí al cadalso. De hecho, la prensa revolucionaria de la época explica claramente que se persigue a las mujeres que quieren ser «hombres de Estado», transgrediendo las leyes de la naturaleza y abjurando de su destino de madres y esposas. El nuevo código civil napoleónico de 1804, cuya influencia ha llegado prácticamente hasta nuestros días, se

9 ASTOLA MADARIAGA, J.: La reforma de la Constitución española desde una perspectiva de género, en ROURA, S. y TAJADURA, J.: La reforma Constitucional, Biblioteca Nueva, Madrid, 2005 , p. 538.

10 «The French expresión l'état c'est l'homme, does not merely signify 'the state is Man in general', but 'the State is the man, the husband in general': BLUNTSCHLI, J.H.: Théorie genérale de l'État, Guillamin et Cie, París, 1967 en su version: The Theory of State, Batoche Books, Ontario (Canadá), 2000, el cual puede consultarse en la p.29: http://www.ecn.bris.ac.uk/het/bluntschli/TheState.pdf. En ese sentido, y trasladándolo al siglo XX, Lucas Verdú considera que el Estado y su ordenamiento jurídico son predominantemente masculinos, precisando que dicha masculinidad no ha de entenderse en el sentido organicista obsoleto del siglo pasado, sino con el alcance de superioridad manifiesta que los varones han tenido en la creación, configuración, articulación y dinámica de las estructuras jurídico-políticas, superioridad que en gran parte conservan todavía. Además, le parece significativo que la mitología hubiese atribuido la fundación de estructuras políticas como la polis y la civitas a Teseo en Atica y a Rómulo en Roma, y que el propio hallazgo semántico del término Estado, aunque para su introductor, Maquiavelo, fuese un tecnicismo neutro, revela en sus traducciones a las principales lenguas europeas su masculinidad: LUCAS VERDÚ, P.: Curso de Derecho Político, Madrid, Tecnos, 1989, pp. 331, 333 y 334. 
encargó de hacer ley positiva dicha «ley natural», consolidando conquistas revolucionarias de los hombres y condenando a las mujeres a la incapacidad legal ${ }^{11}$.

En España, por esas fechas, las mujeres ni siquiera podían presenciar los debates parlamentarios en las tribunas públicas del Congreso, pues les estuvo explícitamente prohibido por los primeros reglamentos de Cortes (1810, 1813, 1821), prohibición que se levanta en $1834^{12}$, aunque solían burlar el Reglamento vistiendo el traje de hombre o usando el talar eclesiástico para esconder sus formas, igual que Concepción Arenal para poder cursar Derecho en la Universidad Complutense de Madrid. Según alguna autora, lo más denigrante es que en las Cortes gaditanas apenas hubo discusión sobre las mujeres, incluso cuando el diputado liberal Muñoz Torrero pronunció, como respuesta a las cuestiones planteadas por los diputados de las colonias sobre la esclavitud, la frase: «si llevamos demasiado lejos estos principios de lo que se dice rigurosa justicia, sería forzoso conceder a las mujeres con los derechos civiles los políticos, y admitirlas en las juntas electorales y en las Cortes mismas» ${ }^{13}$.

En este sentido, resulta difícil la relación entre mujeres y guerra, ya que los espacios de proyección que se le han asignado a cada uno, han sido en todo momento diferentes. También porque su participación se ha visto siempre oscurecida y relegada a un segundo papel, como lo constituye su condición secular de «ciudadanas de segunda clase», y porque en su mayoría, han sido acciones carentes de organización y proyecto, manifestándose y resolviendo numerosos embates de forma espontánea. A pesar de ello resulta curioso que haya sido la figura de una mujer la que hubiera encarnado la patria de las revoluciones liberales del siglo XIX, como lo hizo DELACROIX en la personificación de la libertad. De igual modo, en la Segunda República española, la representación de la nueva España tenía también forma de una mujer joven vestida con la bandera tricolor ${ }^{14}$.

Y es que, las guerras, desafortunadamente, también han sido asunto de mujeres como proveedoras de servicios sanitarios, víveres, etc., exponiendo

11 DUHET, P.M.: Las mujeres y la revolución (1789-1794), Barcelona, Península, 1974, p. 44.

12 FAGOAGA, C., La voz y eL voto de Las mujeres. El sufragismo en España 1877-1931, Barcelona, 1985, pp. 29-30.

13 Diario de Sesiones de las Cortes Generales y Extraordinarias, sesión del 6 de septiembre de 1811, tomo nº 339, p. 1790, citado por: CASTELLS OLIVÁN, I. y FERNÁNDEZ GARCÍA, E.: Las mujeres y el primer constitucionalismo español (1810-1823), en Historia Constitucional, $\mathrm{n}^{\circ}$ 9, 2008, p. 167.

${ }^{14}$ DÍAZ SÁNCHEZ, P.: Las mujeres ante el conflicto social en la España contemporánea, en VVAA: Conflicto y sociedad civil: la mujer en la guerra. Actas de las de las cuartas jornadas sobre la batalla de Bailén y la España contemporánea, Universidad de Jaén, Jaén, 2003, p. 136. 
sus vidas como ha podido observarse en la participación de la mujer en la guerra que yo denominaría «incivil», como milicianas ${ }^{15}$, rehenes o botín de guerra y a la vez sufriendo las agresiones sexuales que los ejércitos, tanto los enemigos como los propios, ejercían sobre las mujeres a lo largo de las campañas ${ }^{16}$.

Un ejemplo lo constituye la heroína local de Bailén, María Bellido, en la lucha contra las tropas napoleónicas el 19 de julio de 1808, de la que se ha dicho que Fernando VII le concedió una pensión vitalicia por su azaña ${ }^{17}$. Otro ejemplo es el de «Agustina de Aragón» (Agustina Zaragoza Doménech), subteniente de infantería, y ello lo demuestra, el hecho de que cuenta con un expediente en el Archivo Militar de Segovia que contiene dos nombramientos: uno por el que se le concede el grado y sueldo de subteniente de infantería, y otro por el que se le reconoce, como premio a los servicios por ella prestados en los Sitios de Zaragoza en 1808 y 1809 , un aumento sobre el sueldo señalado ${ }^{18}$. Aún después de muerta, siguió siendo motivo de honor y de ingresos para su familia, pues su hija Carlota Cobo en $1859^{19}$ y sus nietas $\mathrm{M}^{\mathrm{a}}$ de los Remedios Roca y Jurado Zarago-

15 Como no es el objeto de este estudio, solo cabe mencionar a título ejemplificativo numerosas publicaciones sobre la actuación de la mujer en el frente como combatiente: NASH, M.: Rojas. Las mujeres republicanas en la guerra civil, Taurus, Madrid, 1999; PARSHINA, E.: La brigadista: diario de una dinamitera de la Guerra Civil, La esfera de los libros, 2002; ETCHEBEHERE, M.: Mi guerra de España. Testmonio de una miliciana al mando de una columna del POUM, Alikornio, Barcelona, 2003; FONSECA, C.: Rosario Dinamitera, Temas de Hoy, 2006 (a quien Miguel Hernández le dedicó un poema en: HERNÁNDEZ, M.: Viento del Pueblo, Poética completa, Zero, Madrid, 1976); o mismo la película de Vicente Aranda titulada «Libertarias».

16 Para ello han sido insuficientes los cuatro Convenios de Ginebra de 1949 aprobados el 12 de agosto de 1949 y sus dos Protocolos adicionales de 10 de junio de 1977 que se refieren al trato debido a las personas privadas de libertad, incluidas las condiciones específicas de detención de las mujeres y el trato que éstas han de recibir.

${ }_{17}$ LÓPEZ PEREZ, M.: María Bellido: una mujer para una batalla. Mito y verdad en la heroína de Bailén, en VVAA: Conflicto y sociedad civil: la mujer en la guerra. Actas de las de las cuartas jornadas sobre la batalla de Bailén y la España contemporánea, Universidad de Jaén, Jaén, 2003, pp. 21-84.

18 Los nombramientos son los de 30 de agosto de 1809 y el de 2 de agosto de 1823 . Se conservan en el Archivo General Militar de Segovia — legajo z.166, AGMS 1a sección A. 2646- y son copia de los que se guardan en el de su nieto, don Francisco Atienza Cobos. Sobre esta cuestión: FERNÁNDEZ VARGAS, V.: Las militares españolas. Un nuevo grupo profesional, Biblioteca Nueva, Madrid, 1997, pp.36 y 37.

19 Una instancia fue de 27 de junio de 1827 y la resolución del Senado de 24 de mayo de 1859 sancionada por Isabel II: Ibídem, p. 39. 
za así como doña Elena Josefa Roca ${ }^{20}$, disfrutarían de pensiones concedidas por ser descendientes de la heroína Agustina de Aragón en reconocimiento por los servicios prestados.

En 1774 están fechadas ya algunas prohibiciones por el Ayuntamiento de Pamplona para que las mujeres toreasen con el argumento de «no ser decoroso» (para las mujeres), y en agosto de 1811 fue prohibido por el Ministerio del Interior afirmando que las mismas razones porque no se permite a los niños ni ancianos salir a torear a la plaza, hay para impedírselo a las mujeres; pero sobre todo debe atenderse a las de decencia y decoro público, que se violan con semejante espectáculo, cuyo influjo en la moral es manifiesto, según dije a V.S. cuando me propuso esta idea ${ }^{21}$

Íntimamente ligado al tema de la concepción de la ciudadanía y, por tanto, del alcance de los derechos políticos, aparece el de la extensión de la educación. Los liberales, herederos de los ilustrados por lo que respecta a su fe en la educación como instrumento de perfeccionamiento individual y social, la concibieron como un bien público y del que era responsable el Estado ${ }^{22}$, al disponer el artículo 366 de la Constitución gaditana que en todos los pueblos de la Monarquía se establecieran escuelas de primeras letras. Aunque la preocupación por la educación de las niñas había quedado patente en la Memoria enviada por Jovellanos en 1809 a la Junta Especial de Instrucción Pública, en el Informe Quintana, de $1813^{23}$, que fue la base del Proyecto de Decreto sobre arreglo general de la Enseñanza Pública, presentado a las Cortes en 1814, se propugna una educación diferenciada para niños y niñas; además, la declaración de principios del Proyecto, que establece la primera enseñanza como general e indispensable, se aplica solamente a los niños ${ }^{24}$. El panorama que ofrece el constitucionalismo occidental a lo largo del s. XIX no aporta ninguna novedad significativa en la comprensión del principio de igualdad ante la ley en este aspecto ${ }^{25}$, y hasta el año 1910, la mujer ni siquiera tuvo acceso a la Universidad en España.

20 Por Real Decreto de S.M. el Rey Alfonso XII, San Sebastián, 28 de junio de 1895 y Real Decreto de 28 de julio de 1895 en Aranjuez respectivamente: Ibídem, p. 39.

${ }^{21}$ FEINER, M.: La mujer en el mundo del toro, Alianza Editorial, Madrid, 1995, pp. 40 y 42.

22 BAHAMONDE, A., y MARTÍNEZ, J. A., Historia de España, siglo XIX, Madrid, 1994, pp. 67-68.

${ }^{23}$ QUINTANA, M. L.: Informe de la Junta creada por la Regencia para proponer los medios de proceder al arreglo de los diversos ramos de Instrucción Pública, 1813.

${ }^{24}$ RUIZ BERRIO, 1., Política escolar de España en el siglo XIX (1808-1833), Madrid, 1970, p. 91, citado por López-Cordún, M. V.: La situación de la mujer a finales del Antiguo Régimen (1760-1860), en CAPEL, H. M. (coord.), Mujer y sociedad en España (1700-1975), 2.» cd., Madrid, 1986, p. 97.

${ }^{25}$ Existen no obstante algunos autores como John Stuart Mill y Harriet Taylor Mill de gran importancia para el movimiento feminita. Las conocidas obras de «Ensayos sobre la igualdad 


\section{LA SUCESIÓN EN LA CORONA Y LOS TÍTULOS DE CONSORTE, REGENTE, TUTOR, PRÍNCIPE E INFANTA}

El régimen constitucional iniciado en 1812 conservó la Monarquía, si bien el principio de la soberanía nacional y la división de poderes que informan el texto de Cádiz, unidos en la finalidad de suprimir el anterior poder absoluto del Rey, harán que la institución histórica adquiera una nueva forma, la Monarquía constitucional.

Antes de tratar la cuestión sucesoria, debe hacerse unos breves comentarios para comprender dicha realidad. En España se conoce con el nombre de «Ley Sálica» al auto acordado promulgado por Felipe $\mathrm{V}$, el primer Borbón que reinó en España, el día 10 de mayo de $1713^{26}$, por el que se reglamentaba la sucesión a la Corona de España anteponiendo el derecho de todos los varones del linaje real: directos y colaterales, a heredar el trono antes que las mujeres, admitiéndose únicamente a éstas en el caso de no existir ningún heredero varón ${ }^{27}$.

La combinación de los principios sucesorios contenidos en el «Auto acordado» de 1713 daban como resultado un régimen dinástico de agnación rigurosa: preferencia de mejor línea, orden de primogenitura, derecho de representación y la consiguiente postergación de las mujeres y de sus descendientes a los varones, aunque fueran de mejor grado y línea que éstos, con la excepción, en el supuesto de haberse acabado totalmente las líneas masculinas de sucesión, de nuevo una

sexual» o «el sometimiento de la mujer», entre muchas otras, de Stuart Mill, constituyeron un elemento clave de la expansión e internalización del movimiento sufragista. Consideraba que la desigualdad entre los sexos había privado a la sociedad de una gran reserva de talento, por lo que si las mujeres disfrutaran del «libre uso de sus facultades» así como de «las mismas recompensas y estímulos» que los hombres, se duplicaría «la masa de facultades mentales disponibles al servicio más elevado de la humanidad»: MILL, J.S.: Ensayos sobre la igualdad sexual, Cátedra, 2001. Incluso, importantes teóricos como David Held, han tenido en cuenta los planteamientos de este autor dentro la tradición liberal: HELD, D.: Modelos de Democracia, Alianza Ensayo, Madrid, 1996, especialmente pp. 134 y ss.

26 Edición de «Asuntos acordados» que forma el tomo III de la Nueva Recopilación es el V, tít. VII, Lib. V, edición de 1775.

${ }^{27}$ Ley de 18 de marzo de 1713, incorporada a los Tratados de Utrecht, que contenía la renuncia de Felipe V a la Corona de Francia y disponía que, excluidas las Casas de Francia y de Austria, «en falta del Rey de España y sus descendientes» se llamaría a la sucesión de España a la Casa de Saboya. De otro lado, el 10 de mayo de 1713 se dictó el Reglamento para la sucesión que, aprobado por las Cortes, se promulgó como ley fundamental de la Monarquía y que, al incluirse años después en el tomo que, para completar la recopilación de las leyes de Castilla, se publicó con los autos acordados, se cita como Auto Acordado de 10 de mayo de 1713: RUBIO LLORENTE, F. y ÁLVAREZ JUNCO, J.: El informe del Consejo de Estado sobre la reforma constitucional. Texto del Informe y debates académicos, Centro de Estudios Políticos y Constitucionales, Madrid, 2006, pp. 64 y 65. 
mujer, la más próxima podría suceder, ahora bien, como cabeza de línea, estableciéndose otra vez la agnación rigurosa entre los hijos legítimos que tuviere y sus descendientes.

Paradójicamente, Felipe V debía el trono de España a la forma cognitiva establecida por las leyes de Partidas, que va a derogar, utilizando como argumento el de evitar que la Corona de España saliera de la Casa de Borbón a través de un enlace matrimonial; quebrando de esta manera la tradición jurídica al respecto. Esta disposición fue dada en contra del dictamen corporativo del Consejo de Castilla y tras vencer la resistencia de los procuradores de las Cortes de 1712. En estas Cortes, reunidas en Madrid, intervinieron los procuradores de las ciudades de los Reinos de Castilla, Aragón y Valencia, si bien no todas las habituales y con la ausencia de Navarra, Cataluña y Mallorca. Estos dos últimos territorios, Cataluña y Mallorca, defendían todavía la causa del pretendiente austríaco.

Aprobada la proposición real por las Cortes, se promulga como ley fundamental de la Monarquía el 10 de mayo de 1713. La nueva ley no es bien recibida. Está vigente para Castilla y Aragón y en los otros territorios españoles, cuando se ocupan militarmente por Felipe V; pero cabe dudar de su vigencia en Navarra, cuyas Cortes no lo ratifican, ni tampoco la incluyen en la «Recopilación» de las leyes de Navarra que se publica en 1735. El Auto acordado de 1713 se mantiene a pesar de ello a lo largo del siglo XVIII, pero Carlos IV, al iniciar su reinado, manifestó opinión favorable a su derogación. Así lo propuso a las Cortes en 1789 por el conducto del Conde de Campomanes.

El Conde de Campomanes formula a las Cortes una proposición, que se aprueba sin discusión alguna, en donde se pide la derogación del Auto acordado del año 1713 y el restablecimiento de la ley de Partidas ${ }^{28}$; por su parte, el Rey las

${ }^{28}$ La ley 2 del Título XV de la Partida II (en adelante, Partida 2.15.2) que establece el orden de sucesión de la Corona, dispone que: «el señorío del reyno non lo óbviese si non el fijo mayor después de la muerte de su padre, e este varón siempre en todas las tierras del mundo, doquier que el señorío ovieron por linaje, e mayormente en españa. e por escusar muchos males, que acaecieron o podrían aún ser fechos, puesieron que el Señorío del rey heredasen siempre aquellos que viniesen por la liña derecha. E por ende establecieron que si fijo varón y non óbviese, la fija mayor heredasse el Reyno (...)». Trata pues, de derecho público: familia real, sucesión al trono, oficios palatinos, etc. Ha de señalarse además que las Siete Partidas constituyen para muchos autores el código más importante de la historia del Derecho español, representando a la vez, el apogeo de la recepción en Castilla del Derecho común. En ellas se vierte el saber medieval mediante el aprovechamiento de la filosofía greco-latina, de los textos bíblicos, de la patrística y escolástica, y naturalmente de las obras jurídicas, y ha sido objeto de tres ediciones sucesivas y distintas. Es una obra que siempre se ha atribuido al rey Alfonso X, mediante el cual pretendía unificar la legislación de su reino hasta entonces dividida en una multitud de códigos locales, aunque en realidad, fue de su padre Fernando III de quien partió la idea. Como su nombre da a en- 
sanciona, pero reservará su promulgación para el momento que considere más oportuno. Este acuerdo de las Cortes aprobado por el Rey, por lo tanto, no se promulga, y cuando en 1805 se publica y se promulga la «Novísima Recopilación de las leyes de España», se inserta el Auto acordado de 1713: ley 5, título 1, libro 3.

El Auto acordado de 1713 estuvo vigente hasta 1830, momento en que Fernando VII, ante la expectativa de tener descendencia de su cuarta esposa, doña María Cristina de Borbón, promulga una Pragmática Sanción que no se publicó hasta el 29 de marzo de 1830, en donde restablecía las leyes de Partidas en orden a la sucesión al trono ${ }^{29}$. Sin embargo, las presiones cortesanas favorables a los intereses del hermano del Rey, don Carlos María Isidro durante una grave enfermedad del Rey, le llevan a reponer el Auto acordado de Felipe V el día 18 de septiembre de 1832 (a través del ministro Francisco Tadeo Calomarde), aunque al poco, en el codicilo de su testamento de 1 de octubre de 1832, lo derogaba definitivamente (durante el gobierno dirigido por Francisco Cea Bermúdez) ${ }^{30}$. Fernando VII moría el 29 de septiembre de 1833, proclamándose Reina de España a su hija primogénita Isabel II, abriéndose para España el pe-

tender, el código consta de siete partidas o libros; división que se hace eco de las excelencias atribuidas a ese número por antiguas tradiciones paganas y cristianas (por ejemplo los siete dones del espíritu Santo de los que habla Isaías). Su éxito fue extraordinario, traduciéndose a varios idiomas e incluso rigieron algún tiempo en los Estados Unidos, cuyo Tribunal Supremo (Supreme Court) acudió a ellas para dirimir conflictos entre Estados, o para entender de los recursos y apelaciones presentados por algunos de ellos. Para una mayor profundización sobre las mismas, vid. entre otros: MARTÍNEZ MARINA, F.: Ensayo bistórico-crítico sobre la antigua legislación y principales cuerpos legales de los Reynos de León y Castilla, especialmente sobre el Código de don Alfonso El Sabio, conocido con el nombre de Las Siete Partidas, Madrid, 1808; LÓPEZ, G.: Las siete partidas del sabio Rey Don Alfonso el nono; nuevamente glosadas por el licenciado Gregorio López, BOE, D.L., Madrid, 1985.

29 Convocadas las Cortes en 1789, y reunidos los procuradores en el Real Palacio del Buen Retiro, el Gobernador del Consejo propuso que se reconociese y jurase al Príncipe de Asturias y se derogase el reglamento de sucesión de 1713, cuya cuestión se discutió y examinó a presencia de la Cámara de Castilla. Elevada la petición al Trono, el monarca accedió a derogar el reglamento y restablecer en su fuerza y vigor la ley de Partida. No obstante, por motivos particulares que entonces bubo, se reservó esta ley en la Secretaría de Estado bajo cubierta sellada y con un rótulo que decía "Reservado a solo S.M.». En este depósito se ha conservado hasta que el Sr. D. Fernando VII la ha mandado publicar, por su Real cédula de 29 de marzo de 1830, completando con la promulgación el único requisito que le faltaba a la pragmática sanción: DE LA PEÑA Y AGUAYO, J.: Discurso histórico-legal sobre el derecho de la Princesa Isabel Luisa a la sucesión de la Corona por el fallecimiento sin hijos varones de su padre Fernando VII, con Licencia de D. F. de Benavides, Granada, 1833, pp. 58 y 59.

${ }^{30}$ Estos hechos, han sido denominados «sucesos de la Granja» (lugar de residencia del monarca). Resulta interesante la lectura de: SUÁREZ VERDEGUER, F.: Calomarde y la derogación de la Pragmática, Revista de Estudios Políticos, n 18, 1944. 
ríodo de las guerras civiles carlistas, que tienen como factor desencadenante la derogación del Auto acordado de 1713 o «Ley Sálica», dada por Felipe V a principios del siglo XVIII, pues de este modo, sin la vigencia de la exclusión de la mujer en la sucesión a la Corona, el Infante Carlos María Isidro no podía ser heredero a la misma.

En 1833, DE LA PEÑA Y AGUAYO, Abogado del Ilustre Colegio de la Chancillería de Granada y auditor de Guerra Honorario de los Reales Ejércitos, publicó un discurso histórico legal sobre el derecho de la Princesa Isabel Luisa a la sucesión de la Corona por el fallecimiento sin hijos varones de su padre Fernando VII. Reconoce que si registramos los anales de la Historia de esta Monarquía, no ballaremos un solo becho que diese justo motivo para tner los inconvenientes de la sucesión de las hembras, y para precaver con una nueva ley los males que podrían originarse de la observancia de la ley de Partida; por el contrario, las primeras páginas que se encontraban en tiempo del Sr. D. Felipe V estaban llenas de hechos gloriosos del Reinado de la Reina Isabel, y si no podemos decir otro tanto del de su bija $D^{a}$. Juana, culpa es de su incapacidad mental, mas bien que de su sexo $0^{31}$.

A su vez, este autor explica las verdaderas razones por las cuales considera que se habían producido tales hechos y cómo se llevó a cabo. Relata que cuando Felipe $\mathrm{V}$ estableció la necesidad de una nueva ley de sucesión agnaticia, se produjo un gran desacuerdo en el seno del Consejo de Estado y luego en el Consejo de Castilla. Su presidente, quien más abiertamente se había pronunciado contra la voluntad del Monarca, fue desterrado de la Corte, y además no se convocaron nuevos diputados como debía haberse hecho, preparando todos los medios de conseguir la introducción en España del nuevo Reglamento de sucesión. Según este autor, Felipe $\mathrm{V}$ con los usos y modas francesas que se introdujeron en su corte, quiso introducir también la ley de sucesión de la corona de Francia, con el solo objeto de privar a la casas de Austria del derecho que tenía a la de España, según la ley de Partida, porque faltando la descendencia de María Teresa de Austria, mujer de Luis XIV, debía entrar la sucesión de la corona en la línea de Margarita Teresa, casada con el Emperador Leopoldo I. Mas por el nuevo reglamento se llamó a la casa de Saboya en defecto de la descendencia de Felipe $V$ y la casa de Austria quedó sin ningún llamamiento. De aquí se infiere que no fue el interés del bien público, ni la necesidad del Estado, los que introdujeron en España la ley de agnación, sino el deseo de que no volviese a ocupar el Trono la casa de Austria, con la que se había tenido una guerra tan empeñada y que en el lugar que a ésta

${ }^{31}$ DE LA PEÑA Y AGUAYO, J.: Discurso histórico-legal sobre el derecho de la Princesa Isabel Luisa a la sucesión de la Corona por el fallecimiento sin hijos varones de su padre Fernando VII, ob. cit., 1833, p. 30. 
le correspondia, entrase la casa de Saboya, a la que pertenecía la Reina, que fue la que por esta causa influyó más poderosamente para la formación de la nueva ley ${ }^{32}$.

Las explicaciones de cómo ocurrieron los hechos ocurridos en el mismo lecho de muerte de Fernando VII en relación al derecho de la Princesa Isabel Luisa a la sucesión a la Corona, son harto expresivos: cuando en 1830 se promulgó la pragmática de 1789, fue recibida por el pueblo con el mayor entusiasmo, y también por las autoridades y corporaciones que no hicieron protesta ni reclamación alguna, pero no de igual modo cuando el monarca estaba enfermo ${ }^{33}$.

Si nos circunscribimos al tratamiento de la sucesión de la mujer en la Jefatura del Estado en España en relación al régimen constitucional, que se desarrolla a partir de las Cortes de Cádiz (1812) ${ }^{34}$, debemos observar que ésta, en sus artículos 174 a 184, puso de nuevo en vigor las leyes de Partidas, que regulaban la sucesión al trono (art. 174) «orden regular de primogenitura y representación entre los descendientes legítimos (del rey), varones y hembras (...)» (art.176) «en el mismo grado y línea los varones prefieren a las hembras (...), pero las hembras de mejor línea, o de mejor grado en la misma línea, prefieren a los varones de línea

32 Ibídem, pp. 48-50.

33 Ibídem, pp. 62 y ss. También el Marqués de Miraflores, Conde de Floridablanca publicó una memoria histórico-legal sobre las leyes de sucesión a la Corona de España, en donde afirma que «los medios irregulares con que se obtuvo, no del Consejo, sino de los Consejeros de Castilla, un dictamen favorable, debieron emplearse también para arrancar la aprobación de las Cortes que suscribieron en 1713 a los deseos del Rey» (p. 14). Este autor también se refiere a una de las razones que se alegaban para invalidar la revocación del Auto acordado; la no promulgación, entre cuyos argumentos se encuentra la de que la incorporación del Auto acordado en la Novísima Recopilación formada en el año de 1805 era tácitamente una renovación de su vigor, y una invalidación de la revocación hecha en las Cortes de 1789: MARQUÉS DE MIRAFLORES (Conde De Floridablanca): Memoria bistórico-legal sobre las leyes de sucesión a la Corona de España, Imprenta de D.L.Amarita, 1833.

34 Existen autores que también consideran el Estatuto de Bayona de 6 de julio de 1808 (aunque no fue propiamente una Constitución española) que establece que la «Corona de las Españas y de las Indias será hereditaria en nuestra descendencia directa, natural y legítima de varón en varón, por orden de primogenitura y con exclusión perpetua de las hembras». En defecto de los anteriores establece el llamamiento a favor de diversos sucesores varones, comenzando por el propio Napoleón y sus descendientes, y siguiendo con los descendientes varones del Príncipe Luis Napoleón, los descendientes varones del Príncipe Jerónimo Napoleón. Sólo a falta de todos ellos sucedería el «hijo primogénito, nacido antes de la muerte del último Rey, de la hija primogénita entre los que tengan hijos varones, y a su descendencia masculina natural y legítima, y en caso que el último Rey no hubiese dejado hija que tenga hijo varón, a aquel que haya sido designado por su testamento»: DOMÍNGUEZ-BERRUETA DE JUAN, M. y SENDÍN GARCÍA, M.A.: La igualdad de sexos y el acceso a la Corona, en La Reforma Constitucional. XXVI Jornadas de Estudio celebradas los días 27 a 29 de octubre de 2004, Abogacía General del Estado, Ministerio de Justicia, Madrid, 2005, p. 501. 
o grado posterior». Asimismo (art. 177) el hijo o hija del primogénito del Rey, en el caso de morir su padre sin haber entrado en la sucesión del Reino, prefiere a los tíos, y sucede inmediatamente al abuelo por derecho de representación».

Debemos recordar al respecto que en la actualidad, tras la aprobación de la Constitución española de 1978, rige la preterición de la mujer en dicha sucesión, pues en su artículo 57.1 CE se establece que «la Corona de España es hereditaria en los sucesores de Su Majestad, Don Juan Carlos I de Borbón, legítimo heredero de la dinastía histórica. La sucesión en el trono seguirá el orden regular de primogenitura y representación, siendo preferida siempre la línea anterior a las posteriores; en la misma línea, el grado más próximo al más remoto; en el mismo grado, el varón a la mujer, y en el mismo sexo, la persona de más edad a la de menos». Dicho en términos muy claros; nuestra Norma Fundamental, instrumento máximo creado para la defensa de nuestros derechos y libertades básicas, establece que es preferible que un hombre ocupe el máximo cargo del Estado, la Jefatura, a que lo haga una mujer.

Ello es debido a que cuando se aprobó la Constitución de 1978 se decidió mantener el mencionado orden sucesorio previsto en la ley de partidas, que convirtió en heredero a don Felipe, con preferencia frente a sus dos hermanas primogénitas, Elena y Cristina. Es decir, no volvió a instaurar la Ley Sálica, ni a aplicar la dicción de la Ley de Sucesión franquista ${ }^{35}$ según la cual la mujer no podía reinar, pero sí, en su caso, transmitir a sus herederos el derecho, pero el varón mantiene la preferencia en dicha sucesión ${ }^{36}$.

Asimismo, la Constitución de Cádiz disponía que (art. 183) «cuando la Corona recayese sobre hembra, no podrá elegir marido sin consentimiento de las

${ }^{35}$ La Ley de Sucesión a la Jefatura del Estado aprobada el 26 de julio de 1947 y publicada en el BOE $n^{\circ} 208$ de 27 de julio de 1947, contiene en sus artículos $9^{\circ}$ y $11^{\circ}$, un sistema agnaticio en la sucesión al trono. Por un lado, el artículo $9^{\circ}$ indica cuáles son los requisitos necesarios para acceder a la Jefatura del Estado como Rey o Regente «ser varón y español» aparecen en primer término, seguido por otras condiciones que también se juzgan necesarias: haber cumplido 30 años, ser católico y jurar cumplir las Leyes Fundamentales. Por otro lado, el artículo 11, en su apartado 1 , nos dice que, una vez instaurada la Corona en un Rey que reúna los requisitos mencionados, el orden de sucesión será «el de primogenitura y representación, con preferencia de la línea anterior a las posteriores, en la misma línea, del grado más próximo al más remoto; en el mismo grado del varón a la hembra, la cual no podrá reinar, pero sí, en su caso, transmitir a sus herederos el derecho, de forma que, la primera parte del art. 11, apartado 1, parece seguir las Partidas, pero no es así, inclinándose por un sistema de agnación semejante al que se dio históricamente en la Corona de Aragón.

36 Para mayor profundidad sobre estas cuestiones: RICOY CASAS, R.M.: ¿Qué igualdad? El principio de igualdad y no discriminación por razón de sexo en el ordenamiento jurídico español, Dykinson, 2010. 
Cortes, y si lo contrario hiciere, se entiende que abdica la Corona». Circunstancia no reputada para los varones, como tampoco lo era, en relación al ejercicio de la potestad real, que el marido de la reina no tuviera autoridad ninguna respecto del Reino ni parte en el Gobierno (art. 184) «en el caso en el que llegue a reinar una hembra, su marido no tendrá autoridad ninguna respecto del Reino, ni parte alguna en el Gobierno».

Podemos identificar esta dicción con la del art. 58 de la vigente Constitución española en el que se establece que «la Reina consorte o el consorte de la Reina no podrán asumir funciones constitucionales, salvo lo dispuesto para la Regencia». De este modo, el cónyuge del Rey será Reina, pero no existe igual tratamiento correlativo para el cónyuge de la Reina, quien será tan sólo consorte. Se establece pues una diferenciación en el tratamiento del cónyuge según sea Rey o Reina el que ostente la Jefatura del Estado ${ }^{37}$.

El Anteproyecto de la actual Constitución española hablaba del «consorte del Rey o de la Reina». Para justificar este hecho, muchos señalan que esto se ha producido así, dado que la Comisión de Asuntos Constitucionales, teniendo en cuenta que el artículo 57 CE nombraba como Rey, de forma expresa, a Don Juan Carlos I, redactó en primer lugar «la Reina consorte»y, posteriormente, previendo posibles combinaciones sucesorias futuras, incluyó «el consorte de la Reina», en un intento de crear un artículo testimonio de la situación de ese momento pero, a la vez, imperecedero ${ }^{38}$.

Alguna autora ${ }^{39}$ ha señalado la idea de que, como la consorte del Rey tendrá tratamiento de Reina y sin embargo al consorte de la Reina le está prohibido igual tratamiento, aunque pudiera llevar esto a afirmar que existe una discriminación por razón de sexo a favor de la mujer, en realidad, ocurre lo contrario,

37 Esta circunstancia puede observarse con mayor claridad en el art $1^{\circ}$ del Real Decreto 1368/1987 de 6 de noviembre de 1987, sobre el Régimen de Títulos, Tratamientos y Honores de la Familia Real y de los Regentes, en donde se establece que: «1. El titular de la Corona se denominará Rey o Reina de España y podrá utilizar los demás títulos que correspondan a la Corona, asî como las otras dignidades nobiliarias que pertenezcan a la Casa Real. Recibirá el tratamiento de Majestad. 2. La consorte del Rey de España, mientras lo sea o permanezca viuda, recibirá la denominación de Reina y el tratamiento de Majestad, así como los honores correspondientes a su Dignidad que se establezcan en el ordenamiento jurídico. 3. Al consorte de la Reina de España, mientras lo sea o permanezca viudo, corresponderá la Dignidad de Príncipe. Recibirá el tratamiento de Alteza Real y los honores correspondientes a su Dignidad que se establezcan en el ordenamiento jurídico.

38 DOMÍNGUEZ GARCÍA, N.: El lenguaje jurídico-político: la Constitución española de 1978, La Página, Madrid, 2000, p. 116.

39 VENTURA FRANCH, A.: Las mujeres y la Constitución española de 1978, Instituto Mujer, Madrid, 1999, pp. 136 y 137. 
pues suponiendo que la Constitución no establece diferencias y que el consorte de la Reina tiene el tratamiento de Rey, cuántas veces sería necesario recordar que la que ostenta las funciones asignadas por la Constitución a la Corona es la Reina y no el Rey consorte, dadas las relaciones y concepciones sociales mujer/varón en la actualidad. Varios autores han señalado que esta asimetría terminológica en el tratamiento de los respectivos consortes del Rey y de la Reina, no merecen una reforma de nuestra norma suprema, toda vez que bastaría con la modificación del Real Decreto sobre Régimen de Títulos, Tratamientos y Honores de la Familia Real y de los Regentes ${ }^{40}$, modificación que consistiría en atribuir a los cónyuges regios el mismo estatuto jurídico y el mismo tratamiento ${ }^{41}$.

40 RD 1368/1987, de 6 de noviembre sobre Régimen de Títulos, Tratamientos y Honores de la Familia Real y de los Regentes

${ }^{41}$ En este sentido: REY MARTÍNEZ, FREIXES Y TORRES DEL MORAL en: RUBIO LLORENTE, F. y ÁLVAREZ JUNCO, J.: El informe del Consejo de Estado sobre la reforma constitucional. Texto del Informe y debates académicos, Centro de Estudios Políticos y Constitucionales, Madrid, 2006. Habría dos posibilidades: 1) la primera consistiría en establecer que: «la Reina consorte o el Rey consorte no podrán asumir o ejercer funciones constitucionales salvo lo dispuesto para la Regencia». 2) la segunda posibilidad sería expresar: «la consorte del Rey o el consorte de la Reina no podrán asumir o ejercer funciones constitucionales, salvo lo dispuesto para la Regencia y la tutela». Tal vez debería utilizarse esta última, puesto que Rey o Reina debe ser título exclusivo del descendiente o familiar de Don Juan Carlos o el que sea llamado a suceder y acepte, no de su mujer o de su marido. De hecho, el propio anteproyecto de la CE hablaba del «consorte del Rey o de la Reina». Y me parece que es compatible con un tratamiento puramente protocolario o de cortesía como «Reina» o «Rey» al consorte regio. No obstante, también aquí debemos tener en cuenta que su Majestad la Reina Sofía, como vemos, tiene tratamiento de Reina, por lo que resultaría en este caso obligado introducir su vigencia a partir de su reinado, o una disposición transitoria que limitara los efectos temporales de la reforma a quienes sucedieran en la Corona con posterioridad a su entrada en vigor. Este sería el supuesto que le parece más apropiado a TORRE DE SILVA Y LÓPEZ DE LETONA, J.: Comentario sobre la sucesión en la Corona y su repercusión en la sucesión en los títulos nobiliarios, en XXVI Jornadas de Estudio celebradas los días 27 a 29 de octubre de 2004, Abogacía General del Estado, Dirección del Servicio Jurídico del Estado, Ministerio de Justicia, Madrid, 2005, p.483. Asimismo, según el artículo segundo del Real Decreto 1368/1987, de 6 de noviembre sobre Régimen de Títulos, Tratamientos y Honores de la Familia Real y de los Regentes, se establece que la dignidad del Príncipe (o Princesa) de Asturias le corresponde únicamente al Heredero de la Corona por derecho propio. No obstante, en aplicación de un criterio tradicional en España, el Decreto confiere a su consorte igual dignidad. Asimismo el Príncipe heredero tiene tratamiento de alteza Real, en lo que está igualado a los demás hijos del Rey, a sus propios hijos (que son infantes) y a quienes ejerzan la Regencia (arts. $2^{\circ}, 3^{\circ}, 3^{\circ} \mathrm{c}$ ) y $5^{\circ}$. La consorte del heredero tiene el mismo tratamiento, como igualmente el Príncipe de Asturias consorte. Con lo cual, ha de observarse que la divergencia de tratamiento existente entre el cónyuge de la Reina respecto a la consorte del Rey, no se ha extendido a los utilizados para los consortes del Príncipe o Princesa. 
La Constitución de Cádiz también disponía en sus artículos 189 y 190 que en los casos de vacancia de la Corona la Reina madre formaría parte y presidiría la Regencia provisional, pero una vez se reunieran las Cortes extraordinarias, si no se hallaren reunidas las ordinarias, nombrarán una Regencia compuesta de tres o cinco personas españolas y presidida por quien designasen las Cortes según establecen los artículos 192-194. Como puede observarse, la Reina sólo sería Regente de manera muy provisional, casi excluída por lo tanto de dicha institución ${ }^{42}$. En la vigente Constitución española, según lo dispuesto en su artículo 59, de forma indistinta puede ser regente el padre o la madre del Rey menor de edad, y sólo en su defecto se nombrará como tal al pariente mayor de edad más próximo a suceder en la Corona, y de no haber persona para ocupar dicho puesto, según lo establecido en la Constitución, se nombrará por las Cortes Generales y se compondrá de una, tres o cinco personas.

En cuanto a ser tutora del Rey menor de edad, el art. 198 de la CE de Cádiz establece dicha posibilidad para la persona que el Rey difunto hubiese nombrado en su testamento, y si no lo hubiere nombrado, será tutora la Reina madre, mientras permanezca viuda. En su defecto, será nombrado el tutor por las Cortes. Parece previsible, según la visión que se tenía en el siglo XIX de la mujer, que el Rey ya hubiera designado a una persona diferente a la Reina como Tutor, y en caso contrario, el hecho de que sólo se permitiese ostentar la institución de tutora en el caso de permanecer viuda. Sin embargo, en este caso, una interpretación sistemática del título IV de la Constitución lleva a la conclusión de que se está refiriendo al progenitor supérstite, sea varón o mujer ${ }^{43}$. Quizás muy en la línea de

42 Resulta muy demostrativo de la opinión sobre las reinas regentes el título de la obra: OLIVÁN SANTALIESTRA, L.: Ángeles o demonios: la leyenda negra de las reinas regentes en la historiografía del siglo XIX, en Arenal, Vol. 11, n 1, 2004.

${ }^{43}$ Esta mención a la situación de viuda para ser tutora me hace recordar los anacrónicos criterios en los que se basó la posibilidad del ejercicio al sufragio por parte de las mujeres en los estadios inciales. La primera enmienda sobre el voto de la mujer en el Congreso español tuvo lugar en 1877 pero con escaso éxito, pues los parlamentarios entendieron que ellas mismas no lo querían, pues no era ese su fin ni función en la vida humana. De hecho tuvo escasa repercusión en la prensa del momento, y transcurrió un período de treinta años entre esta enmienda y las siguientes de 1907 en el Senado. En medio de las risas de los parlamentarios solicitaban el derecho de votar, que no el de ser elegida, a la viuda que tuviese patria potestad pues entendían que la misión de la mujer casada era la de estar en el hogar y habría de estar influenciada totalmente por el hombre a quien le debía sumisión. Pero la duda también se cernía en las viudas, pues como algún parlamentario afirmó, «apartándome de todo humorismo diré que es un grave peligro hacer esa distinción entre viuda y casada, y decir que la mujer no tendrá derecho a voto hasta después de que su marido hubiese muerto, porque tal vez movida por pasiones políticas, le indujera a cometer actos censurables». La otra razón era que consideraban que dar el voto a la viuda era entregarlo al 
la mencionada disposición relativa a permitir que la Reina madre fuera tutora del Rey menor mientras permaneciese viuda en la Constitución de Cádiz.

Asimismo debe destacarse que también se establecía distinción en cuanto a la dotación económica otorgada para las Infantas cuando se casaran (art. 216) que para los infantes también al contraer nupcias (art. 217). Así, a las Infantas, se señalaría por las Cortes la cantidad en concepto de dote, y entregada ésta, cesarían los alimentos anuales. En el caso de los Infantes se hace una distinción específica: si al casarse continúan residiendo en España, se les continúa otorgando los alimentos que les estén asignados, pero si se casaran y residieran fuera, cesan dichos alimentos y se les entrega por una vez la cantidad que las Cortes señalen. Puede observarse el diferente concepto utilizado cuando la entrega económica se hace de una sola vez: en el caso de las Infantas tiene su propio concepto, se trata de «dote». Un concepto que, aun no refiriéndose stricto sensu a lo aquí explicado, tiene su origen en el Derecho Romano. Consistía en el patrimonio que la novia o su familia entregan al futuro marido, con la finalidad de contribuir a las cargas económicas que lleva aparejado el matrimonio. Precisamente esta es una de las ex-

cura. En noviembre de 1919, el diputado Burgos Mazo lo intentó de nuevo y presentó un proyecto de ley electoral que otorgaba el voto a todos los españoles mayores de 25 años, sin distinción de sexo, aunque impedía que las mujeres pudieran ser elegibles. El proyecto contenía alguna extravagancia, como que las elecciones se celebrasen en días diferentes: un sábado para la votación de las electoras y el domingo siguiente para la de los electores, aunque eso poco importa, pues el proyecto nunca llegó ni siquiera a debatirse (LAFUENTE, I.: Agrupémonos todas. La lucha de las españolas por la igualdad, Aguilar, 2003, p.52). Un derecho ya reconocido en esos momentos en otros países como Inglaterra. No obstante, tuvo algunos beneficios, pues se produjo el primer movimiento organizativo entre las mujeres españolas, las cuales constituyeron asociaciones, reuniones, celebraron mítines, etc, sin olvidar también la figura individual de muchas mujeres como Carmen Burgos, llegando incluso al Parlamento peticiones de derecho al sufragio. Y quizás por ello, cuatro años más tarde, bajo la dictadura de Primo de Rivera, se resucita esta vieja cuestión. El Estatuto Municipal (un Decreto de abril de 1924 fijó la composición del censo electoral), promulgado con efecto de ley poco después de asumir el poder, y que derogaba la legislación vigente en esta materia desde 1877, otorgó el voto activo y pasivo a las mujeres (electoras y elegidas) en elecciones municipales, aunque con efectos muy restrictivos, ya que las casadas no podían votar «para evitar posibles disensiones en el seno del hogar». Un mes después, el Gobierno ordenó, a la Dirección Nacional de Estadísticas, la inscripción en el censo electoral de todos los varones mayores de 23 años, así como de las mujeres «solteras y viudas», siempre que no sean prostitutas: «dueñas y pupilas de casas de mal vivir», se dice. También se excluye a las casadas, salvo que estén separadas legalmente y el juez haya declarado al marido culpable, cuando el marido esté desaparecido o haya perdido sus derechos civiles por sentencia firme, o cuando la mujer casada tutele a su marido loco o sordomudo. Es decir, «solteras honestas, viudas, divorciadas inocentes, casadas abandonadas y otras diversas casadas afligidas», como expresa atinadamente y con gracia Amelia Valcárcel (VALCÁRCEL, A.: El debate sobre el voto femenino en la Constitución de 1931, Publicaciones del Congreso de los Diputados, Madrid, 2002). 
plicaciones por las cuales para el grupo familiar las mujeres no eran una buena inversión, y por ello fueron en determinadas etapas víctimas preferidas de la denominada «exposición» (ser abandonadas) ${ }^{44}$.

Asimismo debe destacarse que la Constitución de Cádiz (art. 201) y la Constitución de 1869 (art. 79), como la actual de 1978 mencionan expresamente el título de Príncipe de Asturias para el inmediato sucesor de la Corona, no encontrándose sin embargo ninguna referencia a dicho título en las Constituciones de 1837,1845 y 1876 . La ausencia de referencia constitucional fue paliada por el Real Decreto de 30 de mayo de 1850, que estableció que, conforme a las costumbres históricas españolas, los sucesores inmediatos a la Corona, sin distinción de sexo, debían continuar ostentando el título de Príncipe de Asturias. Esta norma despejó las interesadas dudas sobre si el Título podía ser ostentado por una mujer en el caso de que fuera la inmediata sucesora a la Corona. Esta igualdad fue aplicada, mediante orden de 25 de marzo de 1875, por la que se otorgaba el Título de Princesa de Asturias a la Infanta María Isabel Francisca de Asís, hermana mayor de Alfonso XII. Esta doctrina quebró con el Real Decreto de 1 de agosto de 1880 que regulaba el ceremonial que debía seguirse para la presentación

${ }^{44}$ En determinados períodos de la época romana, las mujeres carecían de capacidad política, no transmitían ni podían adoptar, prácticamente tampoco heredaban, les estaba prohibido beber vino, ni siquiera eran designadas con un nombre individual, podían ser abandonadas, vendidas, e incluso su padre o marido tenían derecho de muerte sobre ellas. En el caso del abandono, la referida «exposición», dicho poder podía ser ejercido por el padre inmediatamente sucesivo al nacimiento: los recién nacidos se ponían en el suelo a los pies del pater que, sin necesidad de justificación alguna, podía decidir levantarlos cogiéndolos en brazos (tollere o suscipere liberos) aceptándolos así en la familia, o dejarlos donde habían sido dejados, dando con ello la orden de abandonarlos a su suerte en las aguas del río o en otros lugares, donde, si no eran providencialmente recogidos, estaban destinados a morir. Cuando se trataba de una hija la ceremonia era distinta, y el padre, si decidía acogerla en la familia, debía ordenar explícitamente que se la amamantara (alere iubere) y por lo que parece, esta orden era menos frecuente. (En Grecia, se realizaba colocando a las recién nacidas en una olla de barro y abandonándolas en la calle, generalmente no lejos de casa). Exponer a un hijo varón comportaba siempre una sanción, sin embargo, exponer a una hija no: recogida la primogénita, el padre podía exponer impúnemente a todas las hijas nacidas posteriormente: CANTARELLA, E.: La mujer romana, Universidade de Santiago de Compostela, 1991; íd: Pasado próximo. Mujeres romanas de Tácita a Sulpicia, Cátedra, 1997; íd: La calamidad ambigua. Condición e imagen de la mujer en la antigüedad griega y romana, Ediciones Clásicas, Madrid, 1991. Las XII Tablas en el 451 a.C. establecieron que si un padre vendía un hijo tres veces, después de la tercera venta el hijo salía de la patria potestas, sin embargo, para las hijas bastaba con una sola venta, dado el menor valor de éstas; XII Tab., 2. Cfr. Gayo, 1, 132. THOMAS, Y.: La división de los sexos en el Derecho Romano, en DUBY, G. y PERROT, M. (coord.): Historia de las Mujeres, Taurus, Madrid, 2000, p. 156; MONTERO HERRERO, S: Diosas y adivinas, Trotta, Madrid, 1994 y BORRAGÁN, N.: La mujer en la sociedad romana del Alto Imperio, siglo II d.C., Trabe, Oviedo, 2000, pp. 245 y ss. 
del hijo que esperaba la Reina María Cristina, ya que en dicho Real Decreto se aludía a la presentación solemne del Príncipe o Infanta. Apenas veintidós días después otro Real Decreto (22 de agosto de 1880), sobre Títulos y Honores del Príncipe e Infantes sucesores a la Corona, claramente auspiciado por Cánovas del Castillo, defendió que el Título de Príncipe de Asturias debía ser reservado, como se alegaba que había sido históricamente, a los primogénitos varones del rey y por concesión de éste.

La Constitución española de 1978 no deja lugar a dudas y vincula el título de Príncipe de Asturias al inmediato sucesor a la Corona y, en este caso sí, con independencia de que tal sucesor sea hombre o mujer. Así el artículo 57.2 de la Constitución establece que «El Príncipe heredero, desde su nacimiento o desde que se produzca el hecho que origine el llamamiento, tendrá la dignidad de Príncipe de Asturias y los demás títulos vinculados tradicionalmente al sucesor de la Corona de España», toda vez que no cabe interpretar en sentido excluyente el masculino singular utilizado en este precepto ${ }^{45}$.

A pesar de las cuestiones señaladas, puede concluirse que en la Constitución de Cádiz se le otorga pleno reconocimiento a la capacidad jurídica de la mujer para ser Reina, para ejercer el poder sin tutela y para transmitir su derecho al trono a sus descendientes (aunque recordando que tienen preferencia los varones en la línea de sucesión). Las constituciones posteriores a la de Cádiz, siguen sus principios, que no son otros que los de Partidas. Así, por ejemplo, en el Estatuto Real promulgado el 10 de abril de 1834 a modo de Carta otorgada con la que se pretendía superar la anterior norma fundamental de 1812 y contentar a liberales y moderados, recoge expresamente en su artículo 27, la aplicación de la ley 5a , título XV, partida $2^{a}$, en lo relativo a la Sucesión a la Corona.

\section{LOS TÍTULOS NOBILIARIOS Y LA ABOLICIÓN DE LOS SEÑORÍOS}

La disociación entre las normas que rigen la sucesión en la Corona y en los títulos nobiliarios se consolida tras la petición de las Cortes de Madrid de 1789 de que se derogase el Auto acordado de 1713 volviendo a la entera vigencia de la Partida 2.15.2, aceptada por Carlos IV. Entre la primera fecha y la

45 GÓMEZ SÁNCHEZ, Y.: La sucesión a la Corona: La Reforma del art 57.1 de la CE, en RUBIO LLORENTE, F. y ÁLVAREZ JUNCO, J.: El informe del Consejo de Estado sobre la reforma constitucional. Texto del Informe y debates académicos, ob. cit., pp. 383 y 384; PÉREZ DE GUZMÁN, J.: El Principado de Asturias, Ed. Gijón, 1989; GARRIDO-LESTACHE, A. y MORAL RONCAL, A.M.: La identificación de recién nacidos en la Casa Real Española (1700-2000), Madrid, 2001. 
publicación de la Pragmática Sanción de 29 de marzo de 1830, por la que finalmente se hizo pública aquella decisión, ya se había promulgado la Constitución de Cádiz, que como se ha explicado anteriormente, en sus artículos 174 a 178 se contiene el orden de sucesión a la Corona. De suerte que el proceso de disociación iniciado en 1713 culmina en 1812 y por tanto, desde esta fecha la Partida 2.15.2 deja de ser aplicable a la sucesión en la Corona al ser sustituida por los preceptos constitucionales, si bien continuará rigiendo la sucesión regular en los títulos nobiliarios ${ }^{46}$.

Así, en lo que respecta a la nobleza, la igualdad de derechos entrañó un profundo cambio en la posición política, jurídica y social que este estamento había ostentado en el Antiguo Régimen. Aunque las sucesivas quiebras del régimen constitucional entre 1814 y 1820 así como entre 1823 y 1833 impidieron — salvo en el breve paréntesis del Trienio- no sólo que fuera efectiva la Monarquía constitucional configurada en el texto de 1812, sino que tampoco se llevase a cabo la completa abolición de los privilegios de la nobleza que se inició con el Decreto de Cortes de 6 de agosto de 1811 al incorporar a la nación los señoríos jurisdiccionales, y pese a los principios que informan el nuevo Estado Liberal, tanto las Cortes de las que surge la Constitución de 1812 como el texto de ésta consideraron que los títulos nobiliarios eran una realidad subsistente, sin cuestionar su existencia. Lo que quizás sea explicable teniendo en cuenta que, en este momento histórico la igualdad se proyecta sobre los derechos y deberes civiles y políticos de los ciudadanos, pero no excluye una distinción ulterior en cuanto al «rango y honor» de las personas. Por ello no puede sorprender que las propias Cortes de Cádiz, ya concluida la redacción de la Constitución, concedieran un título de nobleza con Grandeza de España (Decreto de 30 de enero de 1812).

La subsistencia de la institución se aprecia también en el propio Texto constitucional, puesto que al establecer la composición del Consejo de Estado el art. 232 dispuso que este órgano debería incluir, entre otros miembros, «cuatro Grandes de España, y no más, adornados de las virtudes, talento y conocimientos necesarios». Lo que guarda relación con otra circunstancia posterior: que restablecida la Constitución de Cádiz en el Trienio 1820-1823, la antes mencionada ley de 11 de octubre de 1820, pese a suprimir la santiguas vinculaciones de bienes y rentas, dejara subsistentes «los títulos, prerrogativas de honor y cualesquiera otras preeminencias que los poseedores actuales de vinculaciones disfrutan como anejas a ellas...».

Tras la promulgación de la Constitución española de 1978, y especialmente en razón del principio consagrado en su artículo 14, que proclama la igualdad

\footnotetext{
46 STC 126/1997, de 3 de julio de 1997, FJ.7.
} 
ante la Ley de todos los españoles sin que pueda prevalecer discriminación alguna, entre ellas, por razón de sexo, se había planteado la cuestión de si dicha dicción afectaba al régimen sucesorio de los títulos nobiliarios regularmente basado, junto a otros criterios, en la preferencia del varón sobre la mujer.

La regulación de cada título nobiliario se regía por lo dispuesto en su carta de concesión o título constitutivo y a falta de ésta, se venían regulando a través del llamado orden regular o supletorio que se ha asentado históricamente, y en un principio, según las normas de sucesión de la Corona contenidas en las Partidas (II,XV,II) de los siglos XIII y XIV y después, en las más específicas normas dispuestas para los mayorazgos a partir de las Leyes de Tor $0^{47}$, donde se establecía la preterición de la mujer respecto al hombre en dicha sucesión.

Así, en el período 1987-1997, el TS, aunque sin unanimidad interna, consideró en varias ocasiones ${ }^{48}$, que la preferencia del varón sobre la mujer a los efectos sucesorios en el título nobiliario infringía el principio de igualdad. A pesar de todos los argumentos jurídicos que se puedan añadir a los señalados, y a la demanda presentada por cuatro mujeres contra el Estado Español ante el Tribunal Europeo de Derechos Humanos o la apelación al Comité de Derechos Humanos de la ONU, ha habido que esperar a la aprobación de la Ley 33/2006, de 30 de octubre, sobre igualdad del hombre y la mujer en el orden de sucesión de los tí-

47 HERNÁNDEZ-GIL ÁLVAREZ-CIENFUEGOS, A.: La preferencia del varón en la sucesión nobiliaria después de la Constitución, Civitas, Madrid, 1992, p. 235. En el mismo sentido f.d. décimo, último párrafo. Ha de decirse que las Leyes de Toro surgieron principalmente debido a dos necesidades: para dirimir todas aquellas dudas creadas por las diferentes soluciones que daban el Derecho nacional y el Derecho común a casos concretos (aunque no son una recopilación), y por la búsqueda de una regulación legal para la Institución del Mayorazgo. El proceso formal de estas leyes se inicia a través de una petición que se hace en las Cortes de Toledo en 1502 a los Reyes Católicos, y es una Comisión de jurisconsultos castellanos quienes elaboran esta obra que se promulga bajo el Reinado de doña Juana en 1505 bajo las Cortes de Toro (de ahí su nombre). Para una mayor profundización sobre las mismas vid. entre otros; NOLASCO DE LLANO, P.: Compendio de los comentarios extendidos por el Maestro Antonio Gómez a las 83 Leyes de Toro, Lex Nova, D.L., Valladolid, 1981; SANCHO DE LLAMAS Y MOLINA: Comentario crítico-jurídico-literal a las ochenta y tres leyes de Toro, Branchs, Barcelona, 1974.

48 Atendiendo a la abolición del principio de varonía, podemos señalar los siguientes ff.dd. en donde se prescribe, y las respectivas SSTS a los que pertenecen los mismos: f.d. $1^{\circ}$ STS 20 junio 1987, f.d. $2^{\circ}$ STS 27 julio 1987, ff.d 2 $3^{\circ}$ y $4^{\circ}$ STS 28 abril 1989, f.d. $3^{\circ}$ STS 21 diciembre 1989, f.d. $4^{\circ}$ STS 18 abril 1995 con un voto particular formulado por el magistrado Jesús Marina Martínez para mostrar su contrariedad con la misma, f.d. $3^{\circ}$ STS 13 febrero 1996 con un voto particular formulado por el magistrado Luis Martínez-Calcerrada y Gómez oponiéndose a ella, o el f.d. 3ㅇ STS 7 mayo 1996. 
tulos nobiliarios a través de la cual se ha eliminado una barrera más en la preterición de la mujer.

No puede dejar de recordarse el importante hecho histórico de la abolición de los señoríos que se produce en la época de la Constitución Gaditana. La lenta agonía del Antiguo Régimen en España iniciada en 1808, tiene su desenlace en los años inmediatamente posteriores. Las tres disposiciones con las que principalmente se consiguió dicha finalidad fueron las propias Cortes de Cádiz, que aprobaron el Decreto de 6 de agosto de 1811, de abolición de los señoríos ${ }^{49}$; las Cortes del Trienio, que declararon en vigor dicho decreto y realizaron la Ley aclaratoria de 3 de mayo de 1823; y las Cortes Constituyentes de 1836-37 que volvieron a poner en vigor ambas disposiciones y a su vez efectuaron una nueva - y última- Ley aclaratoria de 26 de agosto de 1837 . Esta última norma y también la desvinculación de mayorazgo y la desamortización fueron decisivas para la abolición de los señoríos. Especialmente la segunda, pues fue una operación necesaria en el proceso de transformación de la sociedad estamental e imprescindible para consolidar la revolución burguesa ${ }^{50}$.

\section{CONCLUSIONES}

Puede observarse a través de un breve análisis del principio de igualdad en la Constitución de Cádiz, las contradicciones de su articulado. Al mismo tiempo que expresa atribución de derechos, por ejemplo estableciendo quiénes son españoles o ciudadanos, se establecen numerosas excepciones que dificultan la comprensión de una verdadera aplicación del mismo, o la específica posibilidad que se le da a quienes poseen un título nobiliario. La mera existencia de la esclavitud en sus dominios, y la práctica exclusión de la mujer en la vida po-

49 Las Cortes de Cádiz, en su obra revolucionaria contra el absolutismo y las bases del Antiguo Régimen, no tardaron en afrontar la cuestión de los señoríos. Se inició ésta con una propuesta del diputado valenciano Lloret, el 30 de marzo de 1811, en la que pedía el reintegro de todas las jurisdicciones a la Corona, sin perjuicio de las oportunas compensaciones. Siguieron a esta primera propuesta otras varias, espaciadas en el tiempo (así las de Villanueva, Bahamonde, Caneja, etc), hasta que el 1 de junio del mismo año se inicia, de una forma definitiva, el debate sobre la abolición de los señoríos. Comenzó éste con la presentación de un escrito del diputado José Alonso y Lópeza en el que, tras argumentar la conveniencia de dicha medida, realizaba tres propuestas, y a partir de ahí se fueron aprobando varios artículos de un decreto tras las intervenciones de un gran número de diputados: RUIZ ROBLEDO, A.: La abolición de los señoríos, en Revista de Derecho Político, no 20, 1983-1984, p. 129.

50 TOMÁS Y VALIENTE, F.: Manual de historia del Derecho español, Tecnos, Madrid, 1979, p. 413.

(C) UNED. Revista de Derecho Político

N. ${ }^{\circ} 82$, septiembre-diciembre 2011, págs. 457-486 
lítica, constatan esa idea. De igual modo que ocurrió en el Estado Español al ratificar la Convención sobre eliminación de todas las formas de discriminación contra la mujer el 16 de diciembre de 1983 para excluir de la misma la cuestión relativa al orden sucesorio, también en la Constitución de 1812 se introducen bellas palabras no discriminatorias pero con discriminación a la hora de organizar instituciones.

Precisamente en relación al orden sucesorio, se advierte la misma característica que los últimos siglos e incluso en la actualidad: en ningún momento se ha regulado la igualdad en el acceso al Trono entre los hombres y las mujeres. No restablece la Ley Sálica, ni la exclusión de la mujer ni para sí ni para sus descendientes, pero sí la preferencia del varón sobre la mujer dentro del mismo grado y línea, de forma coincidente con la actual Constitución española.

\section{BIBLIOGRAFÍA}

ÁlvareZ MARTíneZ, C.: Comentarios al Código penal, Tomo I, Madrid, 1848, p. 217, citado por MARTÍNEZ DHIER, A.: La igualdad jurídica de todos los individuos ante la ley: «la vagancia» en la Constitución de Cádiz, en Revista de la Facultad de Ciencias Sociales y Jurídicas de Elche, Vol. 1, 2009.

ANSUÁTEGUI ROIG, F.J.: Orígenes doctrinales de la libertad de expresión, Universidad Carlos III de Madrid y Boletín Oficial del Estado, Madrid, 1994.

ASTOLA MADARIAGA, J.: La reforma de la Constitución española desde una perspectiva de género, en ROURA, S. y TAJADURA, J.: La reforma Constitucional, Biblioteca Nueva, Madrid, 2005.

BAHAMONDE, A., y MARTÍNEZ, J. A., Historia de España, siglo XIX, Madrid, 1994.

BLUNTSCHLI, J.H.: Théorie genérale de 『État, Guillamin et Cie, París, 1967 en su version: The Theory of State, Batoche Books, Ontario (Canadá), 2000, el cual puede consultarse en la p.29: http://www.ecn.bris.ac.uk/het/bluntschli/TheState.pdf.

CANTARELLA, E.: La calamidad ambigua. Condición e imagen de la mujer en la antigüedad griega y romana, Ediciones Clásicas, Madrid, 1991.

- La mujer romana, Universidade de Santiago de Compostela, Santiago de Compostela, 1991.

—Pasado próximo. Mujeres romanas de Tácita a Sulpicia, Cátedra, 1997.

CASTELLS OLIVÁN, I. y FERNÁNDEZ GARCÍA, E.: Las mujeres y el primer constitucionalismo español (1810-1823), en Historia Constitucional, $\mathrm{n}^{\circ} 9$, 2008. 
CLAVERO, B., "Cara oculta de la Constitución: sexo y trabajo», Revista de las Cortes Generales, núm. 10, 1987.

- Amos y sirvientes, ¿primer modelo constitucional?, en Anuario de Historia del Derecho Español, 56, 1986.

DE LA PEÑA Y AGUAYO, J.: Discurso bistórico-legal sobre el derecho de la Princesa Isabel Luisa a la sucesión de la Corona por el fallecimiento sin hijos varones de su padre Fernando VII, con Licencia de D. F. de Benavides, Granada, 1833.

DÍAZ SÁNCHEZ, P.: Las mujeres ante el conflicto social en la España contemporánea, en VVAA: Conflicto y sociedad civil: la mujer en la guerra. Actas de las de las cuartas jornadas sobre la batalla de Bailén y la España contemporánea, Universidad de Jaén, Jaén, 2003.

DOMÍNGUEZ GARCÍA, N.: El lenguaje jurídico-político: la Constitución española de 1978, La Página, Madrid, 2000.

DOMÍNGUEZ-BERRUETA DE JUAN, M. y SENDÍN GARCÍA, M.A.: La igualdad de sexos y el acceso a la Corona, en La Reforma Constitucional. XXVI Jornadas de Estudio celebradas los días 27 a 29 de octubre de 2004, Abogacía General del Estado, Ministerio de Justicia, Madrid, 2005.

DUHET, P.M.: Las mujeres y la revolución (1789-1794), Barcelona, Península, 1974.

ETCHEBEHERE, M.: Mi guerra de España. Testmonio de una miliciana al mando de una columna del POUM, Alikornio, Barcelona, 2003.

FAGOAGA, C., La voz y eL voto de Las mujeres. El sufragismo en España 18771931, Barcelona, 1985.

FEINER, M.: La mujer en el mundo del toro, Alianza Editorial, Madrid, 1995.

FERNÁNDEZ VARGAS, V.: Las militares españolas. Un nuevo grupo profesional, Biblioteca Nueva, Madrid, 1997.

FONSECA, C.: Rosario Dinamitera, Temas de Hoy, 2006 (a quien Miguel Hernández le dedicó un poema en: HERNÁNDEZ, M.: Viento del Pueblo, Poética completa, Zero, Madrid, 1976.

GARCÍA VARELA, R.: La inconstitucionalidad de normas preconstitucionales, La Ley, D-178, 1998-3.

GARCÍA-GALLO, A.: Estudios de Historia del Derecho Privado, Sevilla, Universidad de Sevilla, 1982.

GARRIDO-LESTACHE, A. y MORAL RONCAL, A.M.: La identificación de recién nacidos en la Casa Real Española (1700-2000), Madrid, 2001.

GÓMEZ SÁNCHEZ, Y.: La sucesión a la Corona: La Reforma del artículo 57.1 de la Constitución Española, en RUBIO LLORENTE, F. y ÁLVAREZ JUNCO, J.: El informe del Consejo de Estado sobre la reforma constitucional. Texto del 
Informe y debates académicos, Centro de Estudios Políticos y Constitucionales: Consejo de Estado, 2006.

HELD, D.: Modelos de Democracia, Alianza Ensayo, Madrid, 1996.

HERNÁNDEZ-GIL ÁLVAREZ-CIENFUEGOS, A.: La preferencia del varón en la sucesión nobiliaria después de la Constitución, Civitas, Madrid, 1992.

LAFUENTE, I.: Agrupémonos todas. La lucha de las españolas por la igualdad, Aguilar, 2003.

LÓPEZ PÉREZ, M.: María Bellido: una mujer para una batalla. Mito y verdad en la heroina de Bailén, en VVAA: Conflicto y sociedad civil: la mujer en la guerra. Actas de las de las cuartas jornadas sobre la batalla de Bailén y la España contemporánea, Universidad de Jaén, Jaén, 2003.

LÓPEZ, G.: Las siete partidas del sabio Rey Don Alfonso el nono; nuevamente glosadas por el licenciado Gregorio López, BOE, D.L., Madrid, 1985.

LUCAS VERDÚ, P.: Curso de Derecho Político, Madrid, Tecnos, 1989.

MARQUÉS DE MIRAFLORES (Conde De Floridablanca): Memoria histórico-legal sobre las leyes de sucesión a la Corona de España, Imprenta de D.L.Amarita, 1833.

MARTÍNEZ DHIER, A.: La igualdad jurídica de todos los individuos ante la ley: «la vagancia» en la Constitución de Cádiz, en Revista de la Facultad de Ciencias Sociales y Jurídicas de Elche, Vol.1, 2009.

MARTÍNEZ MARINA, F.: Ensayo histórico-crítico sobre la antigua legislación y principales cuerpos legales de los Reynos de León y Castilla, especialmente sobre el Código de don Alfonso El Sabio, conocido con el nombre de Las Siete Partidas, Madrid, 1808.

MILL, J.S.: Ensayos sobre la igualdad sexual, Cátedra, 2001.

MOLINA PETIT, C.: Dialéctica feminista de la Ilustración, Anthropos, Madrid, 1994.

-El feminismo en la crisis del proyecto ilustrado, Sistema, no 99, 1990.

MONTERO HERRERO, S: Diosas y adivinas, Trotta, Madrid, 1994 y BORRAGÁN, N.: La mujer en la sociedad romana del Alto Imperio, siglo II d.C., Trabe, Oviedo, 2000.

NASH, M.: Rojas. Las mujeres republicanas en la guerra civil, Taurus, Madrid, 1999.

NOLASCO DE LLANO, P.: Compendio de los comentarios extendidos por el Maestro Antonio Gómez a las 83 Leyes de Toro, Lex Nova, D.L., Valladolid, 1981.

OLIVÁN SANTALIESTRA, L.: Ángeles o demonios: la leyenda negra de las reinas regentes en la bistoriografía del siglo XIX, en Arenal, Vol. 11, n 1, 2004.

PARSHINA, E.: La brigadista: diario de una dinamitera de la Guerra Civil, La esfera de los libros, 2002. 
PÉREZ DE GUZMÁN, J.: El Principado de Asturias, Ed. Gijón, 1989.

PULEO, A.: Figuras del otro en la Ilustración francesa. Diderot y otros autores, Escuela Libre Editorial, Fundación ONCE, Madrid, 1996.

- La Ilustración olvidada. La polémica de los sexos en el siglo XVIII. Condorcet, De Gouges, De Lambert y otros, Anthropos, Madrid, 1993.

QUINTANA, M. L.: Informe de la Junta creada por la Regencia para proponer los medios de proceder al arreglo de los diversos ramos de Instrucción Pública, 1813.

REY MARTÍNEZ, FREIXES Y TORRES DEL MORAL en: RUBIO LLORENTE, F. y ÁLVAREZ JUNCO, J.: El informe del Consejo de Estado sobre la reforma constitucional. Texto del Informe y debates académicos, Centro de Estudios Políticos y Constitucionales, Madrid, 2006.

RICOY CASAS, R.M.: ¿Qué igualdad? El principio de igualdad y no discriminación por razón de sexo en el ordenamiento jurídico español, Dykinson, 2010.

ROMERO COLOMA, A.M : El artículo 14 de la Constitución española y su relevancia en el ámbito de la sucesión de titulos nobiliarios, en Actualidad Administrativa, no $47,1997$.

RUBIO LLORENTE, F. y ÁLVAREZ JUNCO, J.: El informe del Consejo de Estado sobre la reforma constitucional. Texto del Informe y debates académicos, Centro de Estudios Políticos y Constitucionales, Madrid, 2006.

RUIZ ROBLEDO, A.: La abolición de los señoríos, en Revista de Derecho Político, $\mathrm{n}^{\circ} 20,1983-1984$.

RUIZ BERRlO, 1., Política escolar de España en el siglo XIX (1808-1833), Madrid, 1970, p.91, citado por López-Cordún, M. V.: La situación de la mujer a finales del Antiguo Régimen (1760-1860), en CAPEL, H. M. (coord.), $M u$ jer y sociedad en España (1700-1975), 2.» cd., Madrid, 1986.

SANCHO DE LLAMAS Y MOLINA: Comentario crítico-jurídico-literal a las ochenta y tres leyes de Toro, Branchs, Barcelona, 1974.

SUÁREZ VERDEGUER, F.: Calomarde y la derogación de la Pragmática, Revista de Estudios Políticos, no 18, 1944.

THOMAS, Y.: La división de los sexos en el Derecho Romano, en DUBY, G. y PERROT, M. (coord.): Historia de las Mujeres, Taurus, Madrid, 2000.

TOMÁS Y VALIENTE, F.: Manual de bistoria del Derecho español, Tecnos, Madrid, 1979.

TORRE DE SILVA Y LÓPEZ DE LETONA, J.: Comentario sobre la sucesión en la Corona y su repercusión en la sucesión en los títulos nobiliarios, en XXVI Jornadas de Estudio celebradas los días 27 a 29 de octubre de 2004, Abogacía General del Estado, Dirección del Servicio Jurídico del Estado, Ministerio de Justicia, Madrid, 2005. 
VALCÁRCEL, A.: El debate sobre el voto femenino en la Constitución de 1931, Publicaciones del Congreso de los Diputados, Madrid, 2002.

VENTURA FRANCH, A.: Las mujeres y la Constitución española de 1978, Instituto de la Mujer, Madrid, 1999.

Title:

Comments on the principle of equality and gender in the Constitution of Cadiz

\section{Summary:}

1. The concept of citizen, a subject of rights, the Constitution of Cadiz. 2.-The Succession to the Crown and the title of Consort, Ruler, Guardian, Prince and Princess. 3.- Titles of nobility and the abolition of the domains. 4.- Conclusions. 5.- Bibliography.

\section{Resumen:}

Este artículo realiza algunos comentarios sobre el principio de igualdad en la Constitución Gaditana de 1812, en concreto, y entre otros, sobre el concepto de ciudadano, los sujetos de derecho, la sucesión en la Corona o los Títulos nobiliarios. Se realiza una descripción de su tratamiento en la misma explicando el contexto en el que se aprobó, y a través de su comparación con la vigente Constitución española de 1978.

\section{Abstract:}

This article makes some comments on the principle of equality in the Constitution of $1812 \mathrm{Cadiz}$, in particular, and among others, the concept of citizenship, the subject of law of succession to the crown or the title. We present a description of their treatment in the same explaining the context in which it was approved, and through comparison with the current Spanish Constitution of 1978.

\section{Palabras clave:}

Igualdad, Discriminación, Constitución de Cádiz, Derechos Fundamentales, Sucesión a la Corona, Títulos Nobiliarios.

\section{Keywords:}

Equality, Discrimination, Cadiz Constitution, Fundamental Rights, Succession to the Crown title. 